China Perspectives

$2010 / 4 \mid 2010$

Rural Migrants: On the Fringe of the City, a Bridge to the Countryside

\title{
Healthcare for Migrants in Urban China: A New Frontier
}

\section{Carine Milcent}

\section{OpenEdition}

\section{Journals}

Édition électronique

URL : http://journals.openedition.org/chinaperspectives/5337

DOI : 10.4000/chinaperspectives.5337

ISSN : 1996-4617

Éditeur

Centre d'étude français sur la Chine contemporaine

Édition imprimée

Date de publication : 15 décembre 2010

ISSN : 2070-3449

\section{Référence électronique}

Carine Milcent, "Healthcare for Migrants in Urban China: A New Frontier», China Perspectives [En ligne], 2010/4 | 2010, mis en ligne le 01 décembre 2013, consulté le 28 octobre 2019. URL : http:// journals.openedition.org/chinaperspectives/5337 ; DOI : 10.4000/chinaperspectives.5337 


\title{
Healthcare for Migrants in
}

\section{Urban China: A New Frontier}

CARINE MILCENT

\begin{abstract}
How can healthcare access for Chinese migrants be improved? ${ }^{(1)}$ Migrant workers face two types of healthcare-access exclusion in the workplace: one is financial (because of their income) and the other is social (because of the lack of social networks in the city). We use 2006 data from a survey of rural migrant workers conducted in five of the most economically-advanced cities. The empirical findings support the hypothesis of a return to the hometown for migrant workers with poor health. Apart from residency permits and income, the social integration of migrant workers is also found to be a decisive factor in healthcare access.
\end{abstract}

$\mathrm{T}$ he growth in Gross Domestic Product (GDP) has been accompanied by an expansion in healthcare expenditure. From under 3 percent of GDP in 1980, this grew to 5.3 percent in $2000,{ }^{(2)}$ increasing even more rapidly in urban than in rural areas. As the percentage of migrants in cities increases, their access to education and healthcare has become an increasingly central issue in China. Who has healthcare coverage? This paper proposes some answers by focusing on rural-urban migrant workers with formal jobs and in regular situations.

On top of their existing 103 million urban migrants, Chinese cities continue to experience a steady migration inflow. In terms of health, one consequence is a falling proportion of the rural population living in extreme poverty, and improvements in the level of nutrition. Life expectancy at birth in 2010 was 74.51 years, ${ }^{(3)}$ which is eight years higher than the world average. As the disastrous famine in the late 1950s resulted in high mortality, the current life expectancy figure represents an enormous improvement within China. Other health indicators such as the infant mortality rate, the underfive mortality rate, and the maternal mortality rate have also registered improvements. ${ }^{(4)}$

However, this expansion of healthcare is for the most part unequally distributed. Economic reforms have had positive effects on GDP and the level of nutrition, but have led to the collapse of the public healthcare network and universal access to basic healthcare. The result is an increase in healthcare inequality. The World Health Organization (WHO) periodically ranks countries according to the inequality of their healthcare systems, in particular their healthcare insurance system. According to the last WHO country classification, the Chinese health sector ranked close to the bottom in terms of the fairness of financial contributions.

To help understand this deterioration, we here present a brief description of the healthcare-insurance system before the economic reforms and its subsequent evolution. In China, before the economic reforms, the healthcare-insurance system was not homogeneous. In urban areas, it depended on large state-owned enterprises (SOE) that took care of workers' medical needs; healthcare in rural areas was determined locally. However, out-of-pocket expenses were close to zero, whatever the healthcare setup.

In urban areas, the dismantling of the large state-owned enterprises (SOE) led to healthcare supplied by smaller-size units. These units quickly ran into difficulties financing their own social insurance. There are two main reasons for this: first, they were smaller than before, so the insurance pool was based on a smaller number of individuals; second, they were responsible for making a profit (with no intervention from the state), but part of that profit was used for social in-

1. I would like to thank Wei Zhong and all of the participants at the CASS seminars (Beijing), Beijing Normal University, and the Sciences Politics seminar at BNU (Beijing). I am also grateful to Thomas Serrurier, Pierre Miege, Andrew Clark, and Richard Balme for helpful comments.

2. S. I. Hossain, "Tackling Health Transition in China," The World Bank: World Bank, Policy Research Paper No. 1813, 1997; National Bureau of Statistics, China Statistical Yearbook 2002, Beijing, China Statistical Press, 2002.

3. Central Intelligence Agency, World Factbook 2010, 2010, https://www.cia.gov/library/publications/the-world-factbook/geos/ch.html.

4. X. Liu and Y. Yi, The Health Sector in China: Policy and Institutional Review, background paper for the World Bank China Health Study, 2004. Available at the website: http://siteresources.worldbank.org/ INTEAPREGTOPHEANUT/Resources/ 502734.1129734318233/policyandinstitutionalreview-final.pdf. 
surance. Facing the risk of collapse in the economic framework, the government was forced to react. It introduced a kind of social insurance with far lower coverage than before. In rural areas, farmers were themselves made responsible for social insurance through a pooling system at the village level. The rapid privatisation of farming was therefore disconnected from the financial burden of social insurance for rural inhabitants. Farms were not obliged to use part of their profits for social insurance, and there was therefore no risk of collapse for the agricultural sector. As such, the government did not have to step in to provide an insurance system for the rural population as it did for the urban population. The result was a degradation and sometimes complete disappearance of the healthcare-insurance system in rural areas.

There is by now a large body of literature addressing the question of health inequality around the world. ${ }^{(5)}$ Various methods of analysis have been developed, some making use of advances in the literature on income distribution and taxation. Works have focused on individual countries as well as on comparing many different countries. ${ }^{(6)}$ In the case of China, however, there is very little literature. Bloom and $\mathrm{Gu}(1997)^{(7)}$ analyse the causes of increasing medical care costs and the deterioration of preventive programmes in some poor areas. Liu and Mills $(2002)^{(8)}$ also focus on the reduction in demand for preventive services. A growing number of papers have considered the effect of the introduction of the New rural Cooperative Medical Scheme (NCMS). Jackson et al. (2005) ${ }^{(9)}$ compare the introduction of NCMS with the out-of-pocket system in Henan Province. Wagstaff et al. (2009) also analyse the introduction of the NCMS, but for different provinces in China, and provide an extensive review of this new literature. However, empirical studies on healthcare and migrants have attracted almost no attention in existing research.

In this paper, we highlight migrants' healthcare exclusion due to both income and their lack of integration in the city. The household registration system (hukou) is interwoven with distribution of services and job opportunities. Most peasants who enter cities are not granted urban citizenship and are treated as "outsiders" to the urban society. The hukou system in fact also has consequences on the income effect. Hukou increases costs significantly, and represents a cost barrier to access equivalent to income loss. We shed light on the importance of both material and social capital, or life conditions, for migrant workers in providing greater access to healthcare. Above all, we provide new evidence on the decisive role of social networks on migrants' healthcare access. Two pieces of work in sociology used qualitative methods to underline the effect of health on the decision to return home. ${ }^{(10)}$ Our empirical findings support the hypothesis of the return home for migrants with health problems. We are the first to highlight this pattern of exclusion using an empirical strategy and to emphasise the importance of social networks, the residence registration system, and the support of family and relatives as a factor in the outcome of treatment in compelling migrants to leave the city.

In Section 2, we present the Chinese context. The description of the data and some preliminary statistics on migrants and healthcare are given Section 3. The econometric model is presented in Section 4. In sections 5 and 6, we present the first econometric results and explore migrants' healthcare access depending on their health status. Section 7 concludes the paper.

\section{The Chinese context}

China's economic reforms have produced remarkable growth in GDP. This growth has been particularly concentrated in certain areas, mainly the major cities in the eastern and south-eastern regions, leading to massive internal migration. Since the late 1970s, the economic take-off in some urban centres has created a huge demand for labour in these areas and triggered a wave of migration. The general GDP growth across the country led to rising labour demand at the local level in most areas, but much less so than in these industrial centres. ${ }^{(I I)}$ The forecast is that by 2020 more than 50 percent of China's total population will live in towns and cities. This implies that in coming years about three hundred million farmers will leave the rural areas. This will be the largest migration mankind has ever experienced.

5. Angus Deaton, "Health, Inequality and Economic Development," Journal of Economic Literature, vol. 41, no. 1, 2003, pp. 113-158.

6. Adam Wagstaff, Eddy van Doorslaer, Hattem van der Burg, Samuel Calonge, Terkel Christiansen, Guido Citoni, Ulf-G Gerdtham, Mike Gerfin, Lorna Gross, and Unto Hakinnen, "Equity in the Finance of Health Care: Some Further International Comparisons," Journal of Health Economics, vol. 18, no. 3, 1999, pp. 263-290.

7. Gerald Bloom and Xingyuan Gu, "Health Sector Reform: Lessons from China," Social Science and Medicine, vol. 45, no. 3, 1997, pp. 351-360.

8. Xingzhu Liu and Anne Mills, "Financing Reforms of Public Health Services in China: Lessons for Other Nations," Social Science and Medicine, vol. 54, no.11, 2002, pp. 16911698 .

9. Sukhan Jackson, Adrian C. Sleigh, Li Peng, and Liu Xi-Li, "Health Finance in Rural Henan Low Premium Insurance Compared to the Out-of-Pocket System," China Quarterly, vol. 181, 2005, pp. 137-157

10. Nansheng Bai and Yupeng He, "Huiliu haishi waichu - Anhui Sichuan ersheng nongcun waichu laodongli huiliu yanjiu" (Return or emigrate? A study on rural return migration in Anhui and Sichuan provinces), Shehuixue yanjiu, vol. 3, 2002, pp. 64-78; Z. Q. Zhang, Y Zhou, S. X. Lu and Y. H. Chen, "Return migration of rural labourer from Western China: Causes and strategies," Stat Res, vol. 24, 2007, pp. 9-15 (in Chinese).

11. Zai Liang, Yiu Por Chen, and Yanmin Gu, "Rural industrialisation and internal migration in China," Urban Studies, vol. 39, no. 12, 2002, pp. 2175-2187. 
This internal migration raises a number of issues. One core issue in China is the conflict between the greater welfare associated with economic reforms and the deterioration of healthcare insurance. While economic reforms have had positive effects on GDP and the level of nutrition, they have also led to the collapse of both the public healthcare network and universal access to basic healthcare. The result has been an increase in healthcare inequality.

There is another element that may also play a role in determining migrants' healthcare access and healthcare expenditure. In Chinese hospitals, family and relatives play a crucial role in the treatment and recovery process. Healthcare providers furnish only minimal accommodation and catering. When someone is in hospital, relatives must be present to support the patient through meals and help with their treatment. The presence of relatives also affects the way in which hospital staff treat the patient. The presence of family and relatives in the city can therefore also be a key component of healthcare access in the city.

In theory, migrants are supposed to claim medical care benefits in the locations where they are registered. Even if most migrants do not have access to urban health insurance, some cities such as Shanghai have developed specific health insurance schemes for migrants. These local policies are increasingly common in China, but still cover only a small percentage of migrants, and the level of coverage is very low. Hence, the hukou system and the need for family support in hospitals push migrants to return to their place of registration. Sociological literature based on hometown surveys indicates this pattern. Health conditions that reduce the capacity to work (including old age, pregnancy, and recent childbirth) push migrants to return home to seek family support and to avoid the high medical and living costs in cities. ${ }^{(12)}$ To soften the distinction between the insured and the uninsured, we should underline that the level of coverage is often fairly low even for the insured.

Leaving rural areas therefore does not produce urban dwellers. A survey conducted by Fudan University on 30,000 migrant workers in major Chinese cities revealed that only 7.6 percent of them are satisfied with their life in the city, and that 68 percent are convinced that the city will not accept their integration. ${ }^{(13)}$

The healthcare system is organised such that hospitals capable of treating serious health conditions are found only in larger cities. For very severe health conditions, migrants can obtain some help from the local government in their place of work or from their employing firms. Migrants may thus prefer to stay in the city in order to obtain adequate healthcare. In this paper, we will therefore distinguish acute health problems from other types of disease or injury.

\section{Migrants in five big cities}

\section{The survey on five cities}

We use data from the Survey of Rural Migrant Workers Health and Social-economic Status in 2006. This survey was conducted by the National Population and Family Planning Commission of China and the Institute of Economics of the Chinese Academy of Social Sciences (CASS). The sample is composed of 2,398 interviewees with health and social-economic status information. The interviewees are rural-urban migrant workers. Rural-urban migrant workers are defined as workers who migrate from rural areas to cities. They come from rural areas and have rural hukou: they do not have permanent urban hukou from the place where they work. As noted above, the type of hukou has serious implications in terms of public service access, including health insurance. The rural-urban migrant workers were selected by their work units. This sample was constructed to be representative of rural-urban migrant workers with a formal job and in a regular situation. Therefore, this sample is composed of migrants in socio-economic situations that are called non-critical. The sample excludes migrants with informal jobs and self-employed migrant workers.

The survey covers fives cities: Chongqing, Dalian, Shanghai, Shenzhen, and Wuhan. These five cities represent five of China's geographical regions, each with their own economic characteristics. All five of these cities have economic indices amongst the highest in the country and contain substantial numbers of rural migrant workers. Dalian represents Northeast China; Shanghai represents East China and is the economic hub of the country; Wuhan represents Central China; Shenzhen represents South China and is archetypal of the Pearl River Delta region, the biggest manufacturing base for exports; Chongqing represents Southwest China and is one of the biggest cities in the country; Northwest China is less developed and contains fewer rural migrant workers.

12. Nansheng Bai and Yupeng He, "Huiliu haishi waichu-Anhui Sichuan ersheng nongcun waichu laodongli huiliu yanjiu," art. cit., 2002; Z. Q. Zhang, Y. Zhou, S. X. Lu and Y. H. Chen, "Return migration of rural labourer from Western China: Causes and strategies," art. cit., 2007; Xiaojiang Hu, Sarah Cook, and Miguel A. Salazar, "Internal migration and health in China," The Lancet, vol. 372, no. 9651, 2008, pp. 1717-1719.

13. "Most migrant workers in cities unhappy: Survey," China Daily, 14 January 2008, http://www.chinadaily. com.cn/bizchina/2008-01/14/content_6391702.htm. 
Table 1. Gender and age by city

\begin{tabular}{l|c|c|c|c}
\hline & Male & \multicolumn{2}{c}{ Age } & Total \\
City & $\%$ & Mean & Std. dev. & Nobs. \\
Dalian & 26.03 & 24.90 & 5.29 & 566 \\
\hline Shanghai & 53.78 & 31.20 & 9.29 & 466 \\
\hline Wuhan & 57.73 & 28.56 & 9.05 & 498 \\
\hline Shenzhen & 45.38 & 26.36 & 7.23 & 525 \\
\hline Chongqing & 51.24 & 30.85 & 8.35 & 2,398 \\
\hline Five Cities & 48.00 & 28.65 & 8.46 & \\
\hline \multicolumn{7}{l}{}
\end{tabular}

Table 2. Education structure

\begin{tabular}{l|c|c|c|c|c|c}
\hline & & & & & \\
City & Dalian & Shanghai & Wuhan & Shenzhen & Chongqing & Five Cities \\
\hline Illiterate & 0 & 2.03 & 0.43 & 0.40 & 1.71 & 1.00 \\
\hline Elementary School & 1.37 & 14.55 & 8.80 & 9.04 & 13.14 & 9.97 \\
\hline Junior Middle School & 54.37 & 53.59 & 57.94 & 63.45 & 52.57 & 56.38 \\
\hline Senior Middle School & 12.84 & 18.05 & 19.96 & 16.27 & 18.48 & 17.35 \\
\hline Vocational Middle School & 19.95 & 1.47 & 2.36 & 2.81 & 2.67 & 5.00 \\
\hline Technical Middle School & 7.38 & 4.60 & 8.80 & 6.63 & 7.62 & 6.92 \\
\hline Junior College & 3.83 & 4.24 & 1.07 & 1.00 & 3.81 & 2.79 \\
\hline College & 0.27 & 1.47 & 0.64 & 0.20 & 0 & 0.54 \\
\hline & $\mathbf{3 6 6}$ & $\mathbf{5 4 3}$ & $\mathbf{4 6 6}$ & $\mathbf{4 9 8}$ & $\mathbf{5 2 5}$ & $\mathbf{2}$ \\
\hline
\end{tabular}

Sources: see Table 1.

Tables 1 and 2 show the sample characteristics. The average age is about 27 and there are no old people in the sample, which is typical of Chinese migrant characteristics. Migrants are younger in Dalian and Shenzhen than in the other three cities. On average, they are older in Shanghai and Chongqing. One explanation may come from the types of work in which migrants are employed. In Dalian, Wuhan, Shenzhen, and Chongging, the sample mainly covers workers in industrial production lines, where jobs are better suited for younger workers. In Shanghai, the sample mainly comes from small companies and service industries where physical requirements may disqualify older migrants. The share of male and female workers is similar across cities.

In China, compulsory education lasts for nine years. In most provinces, these nine years of education include six years of primary school (or elementary school) and three years of junior middle school. Most children start school at the age of seven. After junior middle school, they can choose to leave the education system. Beyond junior middle school there are three types of education: senior middle school (and then college after passing a national exam), vocational middle school, and technical middle school. Most migrants come into the labour market after graduating from junior middle school, and some join the labour market after graduating from vocational middle school or technical middle school; very few come into the labour market after graduating from high school. Dalian has the greatest variance in terms of the level of education, with the smallest percentage of elementary school migrants and the highest percentage of vocational middle school migrants.

\section{Health status}

Health in this survey is measured by questions on whether health reduces the capacity to work. This seems apt, as Chinese migrants often ignore health problems unless they affect their capacity to work. These questions were designed 
Table 3. Measuring Health Condition of Migrant Workers

\begin{tabular}{|c|c|c|}
\hline Question & Variable format & Weight (w) \\
\hline Difficulty in raising hand and bending in the last month & Yes/No & If yes, $w=6$; if no, $w=0$ \\
\hline Difficulty in walking $1 \mathrm{~km}$ in the last month & Yes/No & If yes, $w=6$; if no, $w=0$ \\
\hline Difficulty in climbing stairs in the last month & Yes/No & If yes, $w=6$; if no, $w=0$ \\
\hline Feeling headache or dizziness often in past three months & Yes/No & If yes, $w=3$; if no, $w=0$ \\
\hline Feeling extremely tired in the last month & Yes/No & If yes, $w=4$; if no, $w=0$ \\
\hline Feeling stressed in the last month & $1^{\text {st }}$ to $6^{\text {th }}$ levels & $w=0, \ldots, w=5$ \\
\hline
\end{tabular}

Table 4. Health Distribution by City

\begin{tabular}{|c|c|c|c|c|c|c|}
\hline Province & p25 & p50 & p75 & p90 & Mean & Std. Dev. \\
\hline Dalian & 0 & 0 & 4 & 8 & 2.2 & 3.3 \\
\hline Shanghai & 0 & 0 & 1 & 5 & 1.5 & 3.6 \\
\hline Wuhan & 0 & 1 & 4 & 9 & 3.1 & 4.9 \\
\hline Shenzhen & 0 & 1 & 4 & 8 & 2.7 & 4.2 \\
\hline Chongqing & 0 & 0 & 3 & 8 & 2.4 & 4.4 \\
\hline Total & 0 & 0 & 3 & 8 & 2.3 & 4.2 \\
\hline
\end{tabular}

Source: See Table 1.

Note: The index presented here is Health1, Fan's index, from good health (low values) to bad health (higher values).

by Fan Ming $(2002)^{(14)}$ to rank incapacity or injuries that limit migrant labour supply. Following Fan Ming (2002), a health indicator $($ Health $l)$ is constructed from six objective health questions, of which five are Yes/No and the other is on a scale from one to five. The index is equal to the weighted sum of these variables. Health 1 gives information on health conditions limiting work, and takes values from 0 (very good health) to 30 (very poor health conditions limiting work). The questions and weights are shown in Table 3. Table 4 displays migrants' health conditions. Globally, the population should be in good health, as young urban migrants are there to supply labour. In this survey, Wuhan is the city where migrants have the worst health, and Shanghai the city where migrants are in the best health, independent of the index that is analysed.

\section{Healthcare use}

In this paper, we have two sources of information on healthcare expenditure: healthcare expenditures in the last month and average healthcare expenditures per year. These come from information declared by the migrant herself. Healthcare expenditures over the last month are commonly used as an index of healthcare access. Here, however, the percent- age of individuals with a positive value is very low, and the results using this variable are open to discussion. ${ }^{(15)}$ The second source of information has a number of advantages: the share of individuals declaring such healthcare expenditures is significant, and expenditure over a year is a more general measure of healthcare access.

The health indices listed in Table 3 measure health conditions that limit the capacity to work. Therefore, a priori, all those who answered "Yes" to at least one of the questions should go to visit a doctor. ${ }^{(16)}$ Table 5 shows that only few of them actually do so. In the data, 61 percent of individuals declare a positive average healthcare expenditure figure during the year in question. Dalian is the city where migrants have the least healthcare use.

\section{Health insurance}

Migrants have to claim for insurance reimbursement in the location where they are enrolled. Here, health insurance

14. Fan Ming, Health economics: the effects of health on labour market presentation, Beijing, Social Science Literature Press [Chinese version], 2002.

15. These results are available on request.

16. In urban China, people visit doctors in hospitals. Therefore, in this paper "to go to the hospital" and "to visit a doctor" mean the same thing. 
Table 5. Healthcare Consumption and Insurance by City

\begin{tabular}{|c|c|c|c|c|c|c|}
\hline \multirow[b]{3}{*}{ City } & \multicolumn{5}{|c|}{ Healthcare Consumption } & \multirow{3}{*}{$\begin{array}{l}\text { Having Health } \\
\text { Insurance } \\
(\%)\end{array}$} \\
\hline & \multicolumn{3}{|c|}{ All sample } & \multirow{2}{*}{$\begin{array}{l}\text { Insured } \\
(\%) \text { of } \\
\text { HCE >0 }\end{array}$} & \multirow{2}{*}{$\begin{array}{c}\text { Not insured } \\
(\%) \text { of } \\
\text { HCE > } 0\end{array}$} & \\
\hline & $\begin{array}{l}(\%) \text { of } \\
\text { HCE }>0\end{array}$ & $\begin{array}{l}\text { Mean } \\
\text { HCE }\end{array}$ & $\begin{array}{c}\text { Std. dev. } \\
\text { HCE }\end{array}$ & & & \\
\hline Dalian & 41.6 & 963.9 & $4,116.2$ & 32.8 & 44.5 & 80.0 \\
\hline Shanghai & 63.0 & 563.6 & $1,114.8$ & 64.7 & 57.9 & 28.2 \\
\hline Wuhan & 60.9 & 470.5 & 846.0 & 63.4 & 50.8 & 27.2 \\
\hline Shenzhen & 55.0 & 493.9 & $1,088.6$ & 53.5 & 57.7 & 14.4 \\
\hline Chongqing & 78.1 & 515.1 & $1,405.5$ & 80.4 & 77.9 & 18.3 \\
\hline Total & 61.0 & 560.5 & $1,724.6$ & 63.9 & 53.9 & 31.0 \\
\hline
\end{tabular}

refers to subscribing to health insurance in the city of employment. This insurance is mainly subscribed to by the firm. The term "health insurance" excludes NCMS insurance, to which migrants subscribe in their hometown.

Table 5 shows that the level of insurance varies according to the city. While 80 percent of migrants are insured in Dalian, in Chongqing only 18 percent of migrants are. In addition, healthcare use can depend on having health insurance. In Shanghai and Wuhan, insured individuals have more healthcare use than others do, while in Dalian, Wuhan, and Shenzhen insured individuals have less healthcare use than others. Therefore, the effect of insurance does not seem to be unambiguous.

As noted above, there is no national-level health insurance system for migrant workers in China. Provincial governments and some city governments have their own policies regarding migrant health insurance. The five cities in our survey have their own health insurance systems according to local institutions. Specifically, Dalian and Shanghai provide health insurance for migrant workers, with a scheme different from the regular insurance systems for workers with urban hukou. In Shanghai, the government has a comprehensive social insurance system for migrant workers, including three types of insurance: health insurance, pensions, and work-related injury insurance. At the time of this survey, Shenzhen was in the process of setting up a health insurance system for migrant workers. Wuhan and Chongqing are different from the other three cities in having no health insurance system for migrant workers. However, migrant workers in these two cities, as well as in the three others, have the option of joining the health insurance system for city workers. There are two main benefits for migrant workers in subscribing to a migrant health insurance system rather than to a regular health insurance system. First, the fee for the city worker insurance system is higher than that for migrant health insurance; migrant workers, who earn less than city workers (on average) cannot necessarily afford the higher fee. Second, if a migrant worker participates in the city worker insurance scheme, she cannot then transfer her insurance benefits to other cities (or areas). However, we know that one of the key characteristics of Chinese migrant workers is that they frequently move. Migrants often retain links with their hometown through children, land rights, and so on. If they participate in one city's insurance scheme, they cannot subsequently transfer their insurance benefits to another location.

\section{Rural-to-urban migrants: Sample selection}

\section{Estimation issues}

Who uses healthcare? We would like to measure healthcare access itself, i.e. the possibility of a migrant obtaining access to any form of healthcare. As we are not able to obtain a direct measure of healthcare access, we set up a proxy using the presence of healthcare expenditures during the year. When any healthcare expenditure is observed, we consider the migrant to have access to healthcare. HCA is a binary variable indicating whether the migrant has access to health care, i.e. had positive healthcare expenditure. We then identify the determinants of migrants' health consumption by using a probit model. Since we can see from the preliminary statistics that the city has an effect on healthcare use, we also control the model for the city characteristic effects. ${ }^{(17)}$

17. The Hausman test performed for each model (each column) supports the city fixed-effect assumption. The term "fixed effect probit model" is mainly used when individual fixed effects are considered. Our model can also be viewed as a probit model with city dummies. 
Table 6. Descriptive Statistics of Independent Variables

\begin{tabular}{|c|c|c|c|}
\hline \multirow{2}{*}{\multicolumn{2}{|c|}{ Variable }} & \multicolumn{2}{|c|}{ All sample } \\
\hline & & Mean & Std. dev \\
\hline \multicolumn{2}{|l|}{ Female } & 52.0 & 0.50 \\
\hline \multicolumn{2}{|l|}{ Age (30-40) } & 30.0 & 0.46 \\
\hline \multicolumn{2}{|l|}{ Age over 40} & 12.6 & 0.33 \\
\hline \multicolumn{2}{|l|}{ Junior School } & 56.4 & 0.50 \\
\hline \multicolumn{2}{|l|}{ High School } & 29.2 & 0.45 \\
\hline \multicolumn{2}{|l|}{ College } & 3.3 & 0.18 \\
\hline \multicolumn{2}{|l|}{ Income (in Euro) } & 1,434 & 910.80 \\
\hline \multicolumn{2}{|l|}{ Remittance (in Euro) } & 212 & 263.53 \\
\hline \multicolumn{2}{|l|}{ Health Insurance } & 33.3 & 0.47 \\
\hline \multicolumn{2}{|l|}{ NCMS Insurance } & 21.2 & 0.41 \\
\hline \multicolumn{2}{|l|}{ Fixed-term contract } & 54.8 & 0.76 \\
\hline \multicolumn{2}{|c|}{ Firm size (from 1-small to 3-large) } & 2.28 & 0.26 \\
\hline \multirow{2}{*}{ Sector } & Construction & 7.2 & 0,49 \\
\hline & Manufacturing & 60.2 & 0,30 \\
\hline \multirow{3}{*}{ Ownership } & State-owned & 10.1 & 0,25 \\
\hline & Collective & 6.9 & 0,43 \\
\hline & Foreign or JV & 25.3 & 0,50 \\
\hline \multirow{4}{*}{ Expenditure $>$ Q25 } & Clothing & 22.3 & 0,42 \\
\hline & Transportation & 8.6 & 0,28 \\
\hline & Education & 79.6 & 0,40 \\
\hline & House & 37.3 & 0,48 \\
\hline \multicolumn{2}{|c|}{ More than 2 acquaintances } & 79.8 & 0.40 \\
\hline \multicolumn{2}{|c|}{ Feels socially integrated } & 55.9 & 0.50 \\
\hline
\end{tabular}

Table 6 displays descriptive statistics for all the independent variables used in the estimations.

In a second step, we focus on migrants who have health trouble. In the case of migrants who have a health trouble according to the Fan's health index, we should observe use of healthcare. This is the definition of healthcare access given by Waters (2000). ${ }^{(18)}$ On a population where we should observe use of healthcare, the absence of healthcare consumption is interpreted as a healthcare access issue. When any healthcare expenditure is observed, we consider the migrant to have access to healthcare. The dummy variable for the presence of healthcare expenditure is then interpreted as healthcare access. In Waters's paper, need for healthcare is defined by the self-reported health index. Need for healthcare is here measured by Fan's health index.

If unmeasured variables that affect the outcome are also correlated with the migrant's participation in health insurance (e.g. unobserved migrant characteristics), the results of the probit estimation are likely to be inconsistent. To ensure consistent estimates, we employ instrumental variable (IV) estimation by using instruments that are uncorrelated with unobserved individual characteristics but correlated with health insurance. The firm-size index is a good candidate as an instrument. Indeed, the migrant's participation in a health insurance program will depend on the firm's subscription to health insurance and other such characteristics of the firm. Controlling for industry (manufacturing, construction, or services), the size of the firm is plausibly uncorrelated with unobserved individual characteristics. ${ }^{(19)}$

18. Hugh R. Waters, "Measuring equity in access to health care," Social Science and Medecine, vol. 51, no. 4, 2000, pp. 599-612.

19. We also have information on firm ownership (state-owned firms, joint-venture firms, private Chinese firms, and foreign firms). However, these variables are not good candidates. Indeed, in China, firm ownership is correlated with healthcare access. Stateowned firms often have agreements with certain hospitals (for instance, with military hospitals that are on average of better quality), independent of any participation in an insurance program. 
Table 7. Healthcare Consumption for the Whole Sample

\begin{tabular}{|c|c|c|c|c|c|}
\hline & $\begin{array}{c}\text { (1) } \\
\text { Probit }\end{array}$ & $\begin{array}{c}\text { (2) } \\
\text { Probit }\end{array}$ & $\begin{array}{c}\text { (3) } \\
\text { Probit }\end{array}$ & $\begin{array}{c}\text { (4) } \\
\text { Probit }\end{array}$ & $\begin{array}{c}\text { (5) } \\
\text { Probit }\end{array}$ \\
\hline \multirow[t]{2}{*}{ Good/Fair health } & $0.216^{* *}$ & $0.214^{\star *}$ & $0.232^{* *}$ & $0.234^{* *}$ & $0.240^{* *}$ \\
\hline & $(0.0990)$ & $(0.0992)$ & $(0.0996)$ & $(0.0998)$ & $(0.105)$ \\
\hline \multirow[t]{2}{*}{ Bad health } & $0.577^{* \star *}$ & $0.575^{\star \star \star}$ & $0.596^{\star \star *}$ & $0.590^{\star \star *}$ & $0.706^{* \star *}$ \\
\hline & $(0.181)$ & $(0.182)$ & $(0.182)$ & $(0.182)$ & $(0.197)$ \\
\hline \multirow[t]{2}{*}{ Very bad health } & $0.632^{\star \star \star}$ & $0.634^{* \star \star}$ & $0.677^{\star \star \star}$ & $0.675^{\star \star \star}$ & $0.615^{\star *}$ \\
\hline & $(0.242)$ & $(0.242)$ & $(0.245)$ & $(0.245)$ & $(0.251)$ \\
\hline \multirow[t]{2}{*}{ Gender } & $0.200^{\star *}$ & $0.197^{\star *}$ & $0.279^{\star \star *}$ & $0.267^{\star \star *}$ & $0.250^{* *}$ \\
\hline & $(0.0942)$ & $(0.0950)$ & $(0.0971)$ & $(0.0974)$ & $(0.101)$ \\
\hline \multirow[t]{2}{*}{ Age (30-40) } & $0.419^{\star \star \star}$ & $0.420^{\star \star \star}$ & $0.371^{* \star *}$ & $0.356^{\star \star \star}$ & $0.345^{\star * *}$ \\
\hline & $(0.106)$ & $(0.108)$ & $(0.107)$ & $(0.110)$ & $(0.115)$ \\
\hline \multirow[t]{2}{*}{ Age over 40} & $0.463^{\star \star *}$ & $0.462^{\star \star \star}$ & $0.504^{\star * *}$ & $0.475^{\star \star *}$ & $0.452^{* * *}$ \\
\hline & $(0.153)$ & $(0.157)$ & $(0.154)$ & $(0.158)$ & $(0.160)$ \\
\hline \multirow[t]{2}{*}{ Junior School } & & -0.119 & & -0.186 & -0.174 \\
\hline & & $(0.161)$ & & $(0.163)$ & $(0.165)$ \\
\hline \multirow[t]{2}{*}{ High School } & & -0.0627 & & -0.181 & -0.149 \\
\hline & & $(0.175)$ & & $(0.179)$ & $(0.183)$ \\
\hline \multirow[t]{2}{*}{ College } & & 0.500 & & 0.272 & 0.327 \\
\hline & & (0.311) & & $(0.327)$ & $(0.337)$ \\
\hline \multirow[t]{2}{*}{ Log (Income) } & & & $0.472^{* * *}$ & $0.458^{* * *}$ & $0.397^{* * *}$ \\
\hline & & & $(0.129)$ & $(0.133)$ & $(0.140)$ \\
\hline \multirow[t]{2}{*}{ Log (Remittances) } & & & & & $0.0311^{* *}$ \\
\hline & & & & & $(0.0128)$ \\
\hline \multirow[t]{2}{*}{ Health Insurance } & -0.113 & -0.139 & -0.175 & -0.181 & $-0.238^{* *}$ \\
\hline & $(0.108)$ & $(0.109)$ & $(0.110)$ & $(0.111)$ & $(0.114)$ \\
\hline Number of provinces & 5 & 5 & 5 & 5 & 5 \\
\hline
\end{tabular}

Notes: The reference for health status is "Very good health." Standard errors in parentheses. ${ }^{* *} p<0.01,{ }^{* *} p<0.05,{ }^{*} p<0.1$.

\section{First empirical results}

In the following, we do not take hukou into account in the model, as all of the migrants in this survey are in the same situation: they do not have permanent hukou to work in the urban area. We show the results using the health index as defined by Fan (Healthl). The health-status index is recoded into four groups: Very good health; Good/Fair health; Bad health and Very bad health. However, the results are qualitatively similar when we consider instead a vector of dummy variables for questions about health (as listed in Table 3).

Table 7 displays the results from the econometric model. We find that migrant remittances increase healthcare use. This causality is surprising. Poor health induces higher medical expenditure and so less remittance. Indeed, migrants' remit- tances reduce their net income. We might then expect a negative effect on healthcare use due to lower income.

Healthcare insurance has no positive and significant effect on healthcare use. Controlling only for demographic variables and the level of health, we find no effect of insurance on healthcare use, and when we control for income and migrants' remittances (Table 7, Column 5), we even obtain a negative significant effect. At first sight, this is worrying. The aim of healthcare insurance is to improve healthcare use.

In Section 2, we explained the possibility of selection bias in the data due to inter alia legislative aspects (the hukou and its consequences). To test for selection bias is to test for migrant healthcare exclusion. However, having insurance does not mean being well covered. The level of coverage may differ according to the type of healthcare and the gravity of the illness. In China, the level of coverage is often low. 
Hence, as long as migrants consider their health condition as not being an issue for doing their job, they may ignore it. As the degree of gravity worsens, they react, which does not necessarily mean visiting a doctor in the location where they work; they can instead return to their hometown. They do so partly because in their hometown they benefit from family support, and partly also because they may benefit from health insurance there. Recall that public-insurance benefits can only be claimed in the locations where migrants are registered. Migrants are excluded from the health system program set up for urban citizens with the "right" hukou in their city of employment. ${ }^{(20)}$ Because our survey is conducted in the workplace, these migrants will therefore not have been interviewed.

While migrants may prefer to return to their hometown for more severe health conditions, there is another factor that may prevent migrants with poor health from leaving the cities. As described above, the Chinese health system is organised in such a way that hospital quality varies with the degree of urbanisation, with cities offering better quality healthcare. Given a certain degree of severity in a health condition, ${ }^{(21)}$ staying in the city may be a better option for migrants, as it gives them access to an adequate quality of healthcare. Moreover, the level of co-payment is not so low for more severe health conditions, as municipalities or firms where the migrants work may provide financial subsidies in this situation, regardless of hukou.

We therefore propose two models dependant on the gravity of the health condition. As health indices do not capture lower degrees of severity, one model (Model A) considers migrants with health conditions that do not require highquality healthcare, i.e. health conditions that do not require visiting a city hospital; the second model (Model B) considers migrants with more acute health conditions. ${ }^{(22)}$ We have no variable in hand to identify migrants who may eventually leave the city to deal with health problems. However, we know that there is potentially some subset of the population that is not present in our data due to incidental attrition. Comparing the results for migrants with different degrees of health problems allows us to examine the presence of selection bias.

\section{Healthcare use: A behaviour that depends on health status}

We present the results according to Fan's index. ${ }^{(23)}$ However, we may still have variations in health within a given level of this health index. We thus control for internal varia- tions in health via the vector of the six variables for each of the six health questions in both Models A and B. However, the results are not sensitive to the inclusion of the vector in the regressions. Moreover, in this survey, health insurance subscription is decided by the firm. The results could therefore be affected by the non-exogeneity of the effect of health insurance on healthcare use. As explained above, we resolve this issue with instrumental-variable estimation. The results of such estimation are displayed in Column 6 of each Table. What about the potential non-exogeneous effect of NCMS insurance on healthcare use in the city? In China, the system of insurance is associated with one location. Migrants cannot transfer insurance benefits to another location. Because the NCMS is associated with the hometown, NCMS subscription may have an effect on the decision to return to the hometown, but is not a substitute for the city insurance system. Because we focus on the city of employment (the place where the survey was conducted), the subscription to NCMS insurance should not be an issue here. ${ }^{(24)}$

\section{Migrants' exclusion from healthcare access}

Columns 1 to 3 of Table 8 display the results of Model B. Regarding demographic variables, age is positively associated with healthcare access, and female migrants have better healthcare access than do men. To control for hardship of work, we include variables for industry and type of firm. Only working for a state-owned firm has an effect on healthcare use. Before the economic reforms, all those working in state-owned firms had complete healthcare coverage. The situation now is less clear, as this access has gradually deteriorated and migrants usually do not have access to this insurance. However, with the challenge of migrants' healthcare use, these firms are encouraged to facilitate healthcare access for migrants with more severe health conditions. The level of income acts as a push factor on healthcare use. The lower the income, the less likely the migrant is to use health-

20. As noted above, some works on rural areas suggest that migrants return to their hometowns when they need healthcare. Nansheng Bai and Yupeng He, "Huiliu haishi waichuAnhui Sichuan ersheng nongcun waichu laodongli huiliu yanjiu," art. cit., 2002; Z. Q. Zhang, Y. Zhou, S. X. Lu, and Y. H. Chen, "Return migration of rural labourer from Western China: Causes and strategies," art. cit., 2007.

21. When the degree of gravity is severe.

22. We examined different thresholds to define Models A and B. We used the third quartile and the ninth decile of the Health1 variable; these produce very similar results. The results presented here pertain to the third quartile.

23. We have also considered the unweighted index, which does not change the results.

24. The results without the NCMS index are unchanged. These are available on request. As noted above, the term health insurance is for subscription to health insurance in the city of employment. 
Table 8. Healthcare Consumption for Severe Health Conditions (Model B)

\begin{tabular}{|c|c|c|c|c|c|c|}
\hline & $\begin{array}{l}\text { (1) } \\
\text { Probit }\end{array}$ & $\begin{array}{c}\text { (2) } \\
\text { Probit }\end{array}$ & $\begin{array}{c}\text { (3) } \\
\text { Probit }\end{array}$ & $\begin{array}{c}\text { (4) } \\
\text { Probit }\end{array}$ & $\begin{array}{c}(5) \\
\text { Probit }\end{array}$ & $\begin{array}{c}\text { (6) } \\
\text { IV model }\end{array}$ \\
\hline \multirow[t]{2}{*}{ Gender } & $0.543^{*}$ & $0.555^{\star}$ & $0.705^{\star *}$ & $0.848^{* *}$ & $0.852^{* *}$ & $0.852^{\star *}$ \\
\hline & $(0.318)$ & $(0.321)$ & $(0.334)$ & $(0.352)$ & $(0.352)$ & $(0.339)$ \\
\hline \multirow[t]{2}{*}{ Age $(30-40)$} & $1.271^{* \star *}$ & $1.292^{* * *}$ & $1.220^{\star \star \star}$ & $0.905^{\star \star}$ & $0.905^{\star \star}$ & $1.008^{* *}$ \\
\hline & $(0.364)$ & $(0.369)$ & $(0.378)$ & $(0.428)$ & $(0.429)$ & $(0.414)$ \\
\hline \multirow[t]{2}{*}{ Age over 40} & $0.950^{* *}$ & $0.983^{* *}$ & 0.722 & 0.874 & 0.877 & $1.021^{* *}$ \\
\hline & $(0.462)$ & $(0.464)$ & $(0.480)$ & $(0.545)$ & $(0.544)$ & $(0.514)$ \\
\hline \multirow[t]{2}{*}{ Junior school } & $0.730^{*}$ & $0.805^{\star}$ & 0.713 & 0.536 & 0.544 & 0.702 \\
\hline & $(0.436)$ & $(0.443)$ & $(0.458)$ & $(0.488)$ & $(0.488)$ & $(0.479)$ \\
\hline \multirow[t]{2}{*}{ High school } & $1.069^{* \star}$ & $1.032^{*}$ & $1.133^{* *}$ & 0.903 & 0.922 & $0.939^{*}$ \\
\hline & $(0.532)$ & $(0.533)$ & $(0.551)$ & $(0.576)$ & $(0.573)$ & $(0.561)$ \\
\hline \multirow[t]{2}{*}{ College } & 1.648 & 1.324 & 1.888 & 1.678 & 1.671 & 1.714 \\
\hline & $(1.254)$ & $(1.224)$ & $(1.271)$ & $(1.272)$ & $(1.273)$ & $(1.277)$ \\
\hline \multirow[t]{2}{*}{ Log (Income) } & $0.771^{*}$ & $0.755^{\star}$ & $0.906^{* *}$ & $0.986^{* *}$ & $0.996^{* *}$ & 0.740 \\
\hline & $(0.403)$ & $(0.403)$ & $(0.436)$ & $(0.467)$ & $(0.467)$ & $(0.457)$ \\
\hline \multirow[t]{2}{*}{ Log (Remittance) } & -0.0272 & -0.0236 & -0.0336 & -0.0371 & -0.0363 & -0.0469 \\
\hline & $(0.0394)$ & $(0.0398)$ & $(0.0406)$ & $(0.0432)$ & $(0.0432)$ & $(0.0414)$ \\
\hline \multirow[t]{2}{*}{ Health Insurance } & 0.357 & 0.0620 & $0.851^{*}$ & $0.913^{*}$ & $0.892^{*}$ & $0.919^{*}$ \\
\hline & $(0.393)$ & $(0.421)$ & $(0.453)$ & $(0.478)$ & $(0.474)$ & $(0.530)$ \\
\hline \multirow[t]{2}{*}{ NCMS } & & & -0.124 & -0.130 & & -0.0702 \\
\hline & & & $(0.383)$ & $(0.410)$ & & $(0.384)$ \\
\hline \multirow[t]{2}{*}{ Construction Ind. } & & & 0.471 & 0.546 & 0.550 & 0.380 \\
\hline & & & $(0.695)$ & $(0.719)$ & $(0.720)$ & $(0.687)$ \\
\hline \multirow[t]{2}{*}{ Manufacturing Ind. } & & & -0.186 & -0.224 & -0.226 & 0.00424 \\
\hline & & & $(0.449)$ & $(0.479)$ & $(0.479)$ & $(0.446)$ \\
\hline \multirow[t]{2}{*}{ State-owned firm } & & & $1.311^{* *}$ & $1.274^{\star *}$ & $1.257^{* *}$ & 0.797 \\
\hline & & & $(0.582)$ & $(0.588)$ & $(0.585)$ & $(0.549)$ \\
\hline \multirow[t]{2}{*}{ Collective firm } & & & 0.267 & 0.292 & 0.287 & 0.294 \\
\hline & & & $(0.599)$ & $(0.618)$ & $(0.618)$ & $(0.573)$ \\
\hline \multirow[t]{2}{*}{ Foreign and JV firm } & & & -0.622 & -0.431 & -0.434 & -0.657 \\
\hline & & & $(0.469)$ & $(0.493)$ & $(0.493)$ & $(0.495)$ \\
\hline \multirow[t]{2}{*}{ Fixed-term contract } & & & & -0.200 & -0.180 & -0.315 \\
\hline & & & & $(0.344)$ & $(0.338)$ & $(0.352)$ \\
\hline \multirow[t]{2}{*}{ Clothing expenditures } & & & & 0.545 & 0.551 & 0.607 \\
\hline & & & & $(0.405)$ & $(0.404)$ & $(0.390)$ \\
\hline \multirow[t]{2}{*}{ Transport expenditures } & & & & $-1.628^{* *}$ & $-1.619^{* *}$ & $-1.464^{* *}$ \\
\hline & & & & $(0.783)$ & $(0.781)$ & $(0.669)$ \\
\hline \multirow[t]{2}{*}{ Education expenditures } & & & & 0.543 & 0.542 & 0.305 \\
\hline & & & & $(0.448)$ & $(0.448)$ & $(0.432)$ \\
\hline \multirow[t]{2}{*}{ Housing expenditures } & & & & 0.227 & 0.224 & 0.0628 \\
\hline & & & & $(0.329)$ & $(0.329)$ & $(0.322)$ \\
\hline \multirow[t]{2}{*}{ Acquaintances } & & & & 0.274 & 0.262 & $0.322^{*}$ \\
\hline & & & & $(0.410)$ & $(0.409)$ & $(0.166)$ \\
\hline \multirow[t]{2}{*}{ Feeling socially integrated } & & & & $0.529^{*}$ & $0.531^{*}$ & $0.473^{*}$ \\
\hline & & & & $(0.319)$ & $(0.318)$ & $(0.256)$ \\
\hline Insurance*Dalian & & $2.071^{* \star}$ & & & & \\
\hline & & $(1.041)$ & & & & \\
\hline Number of provinces & 5 & 5 & 5 & 5 & 5 & 5 \\
\hline
\end{tabular}


care. The financial domain is then one determinant of migrants' exclusion from healthcare use.

We here focus on more severe health conditions. The optimal behaviour is therefore to stay in the city in order to benefit from better-quality hospital care. First of all, we find that education, migrant remittances, and health insurance all play their expected role: education increases healthcare access; remitting to the rural family has a negative effect on healthcare use; and insurance positively and significantly influences healthcare use. Hence, on the sample where we suspect selection to be less of a problem, we obtain the expected correlations.

Table 9 displays the results from Model A. First, education has a negative and significant effect on healthcare access. With Model B, we found that education has a positive and significant effect on healthcare use. In the light of potential selection, when people have health problems, but not very severe ones, the higher the level of education, the more likely it is they will return to their hometown. Those who do not leave the city of employment are those who are not excluded from the healthcare system for some reason that we have not yet identified, ${ }^{(25)}$ or those who cannot leave, possibly for financial reasons or due to a lack of family support in the hometown. The term "floating" for migrants is sometimes exaggerated. Some no longer have any contact with their hometown.

Second, remitting has a positive and significant effect on healthcare that was not found with Model B. We explain this result as reflecting selection. Migrants who remit are those who have contact with their hometown. Therefore, these are the ones who leave the place of work when their health is bad enough. This selection effect therefore leads to a sample with only a small percentage that has healthcare use and remit. As income plays a strong positive role in healthcare use, those who do not have healthcare use are the poorest, whatever the level of remittance.

Health insurance has a significant negative effect on healthcare use. This effect can also be viewed as reflecting selection. With Model B, we found a positive effect of health insurance. This result suggests that the level of coverage for migrants in the city of employment is not enough to allow them to have healthcare use there. Migrants who can afford to return to the hometown and who still have contacts in the hometown therefore prefer to return to the hometown.

In addition, Table 5 indicated that the percentage of insured migrants in Dalian is about three times that in the other cities, and that mean health expenditures in Dalian are about 80 percent higher than those in the other cities. Even so, migrants have less healthcare use than in the other cities. To control for any specific Dalian effect, we thus add an interaction variable between the index for being a migrant in Dalian and being insured. Adding a specific Dalian effect does not change the results. Likewise, all of the models have been re-estimated without the observations from Dalian, which did not change the results.

The selection bias thus appears clearly. Health insurance and education have a negative impact on healthcare use, whereas remitting induces greater healthcare use. These results are counterintuitive and are opposite those in Model B. In terms of selection bias, however, these results make sense. Due to this bias, the sub-sample of migrants with healthcare use is composed of those who do not have enough contact with the hometown to return there. Therefore, our empirical findings highlight two forms of exclusion: i) exclusion for financial reasons - migrants cannot afford healthcare use or the cost of returning to their hometown; ii) the results confirm the hypothesis of exclusion from healthcare use in the city of employment for migrants with bad health.

\section{Integration into the city}

In Model B, the sample is composed of individuals who have health problems that limit their ability to work. Therefore, healthcare use can be interpreted as healthcare access. ${ }^{(26)}$ We now add indices of integration into the city to the model (in Columns 4 to 6 of Tables 8 and 9). The survey includes a number of different questions on life conditions. We introduce expenditures as life-condition indicators. Specifically, we use clothing, transportation, housing, and education expenditures as proxies for life conditions. With respect to education, the presence of such expenses means that a child lives with the migrant. In China, the majority of migrant children live in the rural area with their grandparents. Apart from financial reasons, another consideration is that migrant children have no access to public schools due to hukou. Individuals only have access to public services in the town of their residency permit. As children only have access to public schools in the place where they are registered, migrant children who live with their parents are obliged to attend private schools. In addition to the subscription fee, parents have to pay additional fees for not having the right hukou. Therefore, education expenses are a good proxy for better life conditions. Likewise, spending money on transport says a lot

25. We present the determinants in the next section.

26. Hugh R. Waters, "Measuring equity in access to health care," art. cit., 2000. 
Table 9. Healthcare Consumption for Bad Health Conditions (Model A)

\begin{tabular}{|c|c|c|c|c|c|c|}
\hline & $\begin{array}{l}\text { (1) } \\
\text { Probit }\end{array}$ & $\begin{array}{c}\text { (2) } \\
\text { Probit }\end{array}$ & $\begin{array}{c}\text { (3) } \\
\text { Probit }\end{array}$ & $\begin{array}{c}\text { (4) } \\
\text { Probit }\end{array}$ & $\begin{array}{c}\text { (5) } \\
\text { Probit }\end{array}$ & $\begin{array}{c}(6) \\
\text { IV model }\end{array}$ \\
\hline \multirow[t]{2}{*}{ Gender } & $0.229^{* *}$ & $0.227^{\star *}$ & $0.241^{* *}$ & 0.146 & 0.145 & 0.100 \\
\hline & $(0.108)$ & $(0.108)$ & $(0.109)$ & $(0.113)$ & $(0.113)$ & $(0.107)$ \\
\hline \multirow[t]{2}{*}{ Age (30-40) } & $0.233^{*}$ & $0.232^{*}$ & $0.210^{*}$ & 0.00881 & 0.00905 & 0.00515 \\
\hline & $(0.124)$ & $(0.124)$ & $(0.125)$ & $(0.137)$ & $(0.137)$ & $(0.131)$ \\
\hline \multirow[t]{2}{*}{ Age over 40} & $0.370^{* \star}$ & $0.370^{\star *}$ & $0.305^{*}$ & 0.228 & 0.233 & $0.327^{*}$ \\
\hline & $(0.172)$ & $(0.172)$ & $(0.175)$ & $(0.183)$ & $(0.183)$ & $(0.174)$ \\
\hline \multirow[t]{2}{*}{ Junior school } & $-0.350^{*}$ & $-0.351^{*}$ & $-0.355^{\star *}$ & $-0.481^{* \star \star}$ & $-0.482^{\star \star \star}$ & $-0.456^{* *}$ \\
\hline & $(0.180)$ & $(0.180)$ & $(0.181)$ & $(0.187)$ & $(0.187)$ & $(0.179)$ \\
\hline \multirow[t]{2}{*}{ High school } & $-0.344^{*}$ & $-0.345^{*}$ & $-0.337^{*}$ & $-0.461^{* *}$ & $-0.459^{* *}$ & $-0.474^{* *}$ \\
\hline & $(0.199)$ & $(0.199)$ & $(0.200)$ & $(0.206)$ & $(0.206)$ & $(0.199)$ \\
\hline \multirow[t]{2}{*}{ College } & 0.133 & 0.132 & 0.103 & 0.0162 & 0.0160 & 0.0478 \\
\hline & $(0.356)$ & $(0.356)$ & $(0.358)$ & $(0.364)$ & $(0.364)$ & $(0.353)$ \\
\hline \multirow[t]{2}{*}{ Log (Income) } & $0.372^{\star *}$ & $0.371^{* *}$ & $0.329^{* *}$ & 0.121 & 0.118 & 0.103 \\
\hline & $(0.150)$ & $(0.150)$ & $(0.154)$ & $(0.164)$ & $(0.164)$ & $(0.158)$ \\
\hline \multirow[t]{2}{*}{ Log (Remittance) } & $0.0385^{\star \star \star}$ & $0.0385^{\star \star \star}$ & $0.0396^{* * *}$ & $0.0494^{\star \star \star}$ & $0.0494^{\star \star *}$ & $0.0482^{\star \star *}$ \\
\hline & $(0.0136)$ & $(0.0136)$ & $(0.0137)$ & $(0.0141)$ & $(0.0141)$ & $(0.0133)$ \\
\hline \multirow[t]{2}{*}{ Health Insurance } & $-0.308^{\star *}$ & $-0.314^{\star *}$ & $-0.305^{\star \star}$ & $-0.338^{\star \star \star}$ & $-0.336^{\star \star \star}$ & $-0.133^{*}$ \\
\hline & $(0.120)$ & $(0.126)$ & $(0.125)$ & $(0.130)$ & $(0.130)$ & $(0.076)$ \\
\hline \multirow[t]{2}{*}{ NCMS } & & & 0.0958 & 0.0596 & & 0.00852 \\
\hline & & & $(0.128)$ & $(0.130)$ & & $(0.123)$ \\
\hline \multirow[t]{2}{*}{ Construction Ind. } & & & $0.472^{\star *}$ & $0.561^{\star *}$ & $0.566^{\star *}$ & $0.622^{\star \star \star}$ \\
\hline & & & $(0.218)$ & $(0.223)$ & $(0.223)$ & $(0.220)$ \\
\hline \multirow[t]{2}{*}{ Manufacturing Ind. } & & & 0.171 & 0.161 & 0.166 & 0.210 \\
\hline & & & $(0.151)$ & $(0.154)$ & $(0.154)$ & $(0.146)$ \\
\hline \multirow[t]{2}{*}{ State-owned firm } & & & 0.0239 & 0.0135 & 0.0156 & -0.0173 \\
\hline & & & (0.181) & $(0.185)$ & $(0.185)$ & $(0.181)$ \\
\hline \multirow[t]{2}{*}{ Collective firm } & & & 0.192 & 0.119 & 0.118 & 0.115 \\
\hline & & & $(0.218)$ & $(0.222)$ & $(0.222)$ & $(0.210)$ \\
\hline \multirow[t]{2}{*}{ Foreign and JV firm } & & & 0.107 & 0.0903 & 0.0830 & -0.102 \\
\hline & & & $(0.182)$ & $(0.186)$ & $(0.185)$ & $(0.188)$ \\
\hline \multirow[t]{2}{*}{ Fixed-term contract } & & & & -0.0655 & -0.0668 & -0.151 \\
\hline & & & & $(0.117)$ & $(0.117)$ & $(0.112)$ \\
\hline \multirow[t]{2}{*}{ Clothing expenditures } & & & & -0.191 & -0.192 & $-0.214^{*}$ \\
\hline & & & & $(0.136)$ & $(0.136)$ & $(0.128)$ \\
\hline \multirow[t]{2}{*}{ Transport expenditures } & & & & $-0.503^{\star \star \star}$ & $-0.506^{\star \star \star}$ & $-0.460^{* * *}$ \\
\hline & & & & $(0.187)$ & $(0.187)$ & $(0.176)$ \\
\hline \multirow[t]{2}{*}{ Education expenditures } & & & & $-0.461^{\star \star \star}$ & $-0.458^{\star \star \star}$ & $-0.417^{\star * *}$ \\
\hline & & & & $(0.152)$ & $(0.152)$ & $(0.146)$ \\
\hline \multirow[t]{2}{*}{ Housing expenditures } & & & & $-0.376^{\star \star \star}$ & $-0.377^{\star \star *}$ & $-0.386^{\star \star *}$ \\
\hline & & & & $(0.119)$ & $(0.119)$ & $(0.114)$ \\
\hline \multirow[t]{2}{*}{ Acquaintances } & & & & $0.380^{* \star *}$ & $0.384^{* * *}$ & $0.372^{* * *}$ \\
\hline & & & & $(0.133)$ & $(0.133)$ & $(0.125)$ \\
\hline \multirow[t]{2}{*}{ Feeling socially integrated } & & & & 0.0633 & 0.0614 & 0.0234 \\
\hline & & & & $(0.111)$ & $(0.110)$ & $(0.105)$ \\
\hline Insurance*Dalian & & 0.0654 & & & & \\
\hline & & $(0.401)$ & & & & \\
\hline Number of provinces & 5 & 5 & 5 & 5 & 5 & 5 \\
\hline
\end{tabular}


about life conditions. In China, migrants in extreme situations do not have houses. They live in tents or prefab housing close to their job. Therefore, transportation expenses suggest that migrants live in better conditions. In conclusion, education and transportation expenses are proxies for integration into the city.

In Model B (Table 8), all of the expenses have a positive effect on healthcare access except for transportation expenditures. As noted above, migrants with transportation expenditures are more likely to have real accommodation rather than a tent or prefab housing close to their place of work. However, transportation expenditure necessarily reduces migrants' disposable income (going to work leads to transportation expenditures). Controlling for income, the type of job, and other types of expenditures, this may explain the negative effect. We have also introduced control variables for the type of work contract and ownership of durable goods: motorbike, bicycle, VCD/DVD, TV, washing machine, mobile phone, microwave or oven, refrigerator, gas stove, and computer. Controlling for social capital and expenditures, these new variables have no impact on healthcare access. Moreover, we have information on family structure, but this has no effect on migrants' healthcare access either. ${ }^{(27)}$

With respect to the social networks, we apply information on the presence of networks, the number of acquaintances or friends, and the way in which the migrant obtained her job. Having friends or acquaintances and being in a better socio-economic situation are two different phenomena. Friends or acquaintances can provide help in case of worsening health. Social networks thus present one reason to remain in the city despite the hukou, a legislative incentive to leave, and regardless of the individual's health. Social integration has a very significant effect on healthcare access, with a marginal effect of about 60 percent. We also find that having friends or acquaintances acts as a significant positive factor in healthcare access, with a marginal effect of 67.3 percent.

On the selected sample, the social network also explains healthcare use. In Model A, we find that having friends or acquaintances acts as a significant positive factor in healthcare use. This positive and significant effect of social networks is echoed in Model B, where the marginal effect is 45 percent. One of the main results of this paper is then the importance of the network and social capital on the healthcare access of migrant workers. Networks act as a push factor in determining healthcare access and allow migrants to obtain access to healthcare regardless of hukou.

\section{Conclusion}

This paper uses data from the Survey of Rural Migrant Workers' Health and Social-economic Status in 2006, covering five cities in China: Chongqing, Dalian, Shanghai, Shenzhen, and Wuhan. These five cities are among China's most industrialised and with the most rural migrant workers. They represent China's five geographical regions with their respective economic characteristics. Using this dataset, the results highlight two exclusion factors: a financial factor (income) and a social factor (the social networks in the city). We present new evidence on the determinants of healthcare use for migrant workers. While financial support is one of the key factors, as expected, another is the social network and the feeling of being socially integrated. This sheds light on the ability of social networks to tackle exclusion from healthcare access.

Age and being a woman increases the need for healthcare use. The propensity to use healthcare is higher for migrants working in state-owned firms. In addition, remitting to the rural family has a negative effect on the propensity for healthcare use. Finally, education and health insurance contribute to a higher propensity for healthcare use.

There is no national-level health insurance system in China. The right to healthcare insurance and other benefits depends on a permanent residence registration system, the hukou. Individuals are only supposed to claim medical care benefits in the locality where they are registered. Migrants are therefore excluded from urban public health insurance and have to return to their place of registration in order to take advantage of rural public health insurance. Due to these legislative factors, migrants are excluded from healthcare use in their city of employment. In addition, in Chinese hospitals, family and relatives play a crucial role during treatment, as hospitals provide only a minimum level of accommodation and catering. When someone is in hospital, relatives need to be present to support the patient with meals and in helping with their treatment, not to mention the psychological impact of family support on patient recovery. The presence of relatives is therefore an important factor in how individuals recover. Hence, the hukou emphasises both income and the need for family support in hospitals as factors pushing migrants to return to their place of registration. However, these "push factors" are softened by the organisation of the Chi-

27. We do not present the results controlling for "the way in which the migrant obtained their job," family structure, and the ownership of durable goods, as none of the estimated coefficients were significant, and their inclusion does not change the other results. 
nese health system, in which hospital quality varies according to the level of urbanisation, with cities offering the best quality of healthcare. Individuals with severe health conditions will have access to adequate healthcare quality in a city hospital, so staying in the city may be the best option for these migrant workers. In this paper, we thus distinguish two models of healthcare use according to the gravity of the health condition.

As long as migrants do not consider their health problems to be an issue in terms of doing their job, they may ignore them. When the gravity of their condition becomes an issue for their work, they react. Reacting does not necessarily mean a visit to a doctor in their city of employment. As noted above, the hukou acts as a "push" factor on income and the lack of social network to exclude them from healthcare use in the city, and they may then return to their hometown. As our survey is conducted in the city of employment, migrant workers who return to their hometowns do not appear in this survey. This selection bias is apparent in our empirical results; migrants who can afford to return to their hometown and who still have contacts in their hometown do indeed return there.

Apart from residency permits and income, we last show that social networks (having friends or acquaintances) stand out as a significant determinant of healthcare access. This highlights the importance of migrant networks in healthcare access. Feeling socially integrated also has a strong positive effect on healthcare access for migrant workers with poor health. As such, social integration seems to be a key factor influencing healthcare access. But what about those who cannot afford to return to the hometown and those who no longer have contact with relatives in their hometown? Should they remain outside the healthcare system in their city of employment without any other options? Targeting this population will allow us to define the specificity of this population (the younger tier, the older tier, females?) and to establish an adequate healthcare-access policy.

In this paper, we use data from migrants selected by their work units. These migrants have formal jobs and are in a regular and non-critical situation. The study does not cover the bottom tier of the migrant population. Our results thus give a much less critical picture than the reality. However, even within this rosier picture we have identified some difficult situations that indicate implementation of an adequate and efficient health policy as a priority.

One efficient policy to improve migrants' healthcare access in China would be to focus on improving their social integration in the city in which they work. One way is to build up migrants' social capital by improving their networks. Resident committees may be the perfect vector for such a policy. Resident committees are defined at the neighbourhood level in urban areas in China, and are the place where nominated residents manage neighbourhood affairs and state-citizen interactions. To data, migrants have not always been well integrated into these committees, even if they have a "real" house. Encouraging committees to include migrants could therefore be a good way of improving migrants' healthcare access.

We have shown the importance of integration for migrants' healthcare access. However, we have not explained the mechanism behind this result. It would be of interest to determine the channel through which integration affects healthcare access: via better information, for example? Via interactions with local workers influencing the behaviour of migrant workers? It is also important to know whether this integration process affects only healthcare access or other domains of life as well, such as children's education. • 